\title{
Conclusions and the Future
}

\author{
Dima Jamali
}

This book offers an interesting selection of readings that deepen our understanding of CSR in the Middle East region. Through an assorted selection of coverage, examples and cases, it ponders the multiple facets of CSR in the region, including philanthropy; strategic giving; social entrepreneurship; internal CSR and responsible HR management practices; effective CSR integration in SMEs; CER and its evolution; CSR reporting and lingering challenges in this respect; as well as the relevance and applicability of CSR and corporate citizenship to a wider spectrum of societal actors and institutions. The various contributions have also nicely captured and reiterated the commitment to CSR in the Middle East, and the need for partnerships and joint initiatives that collectively build human capacity and strengthen the fabric of the social community. In essence, the future bodes well for CSR in the Middle East, and the common challenge we face is to shift to more organized forms of giving that leverage the strong traditions of philanthropy in the region but also channel them more effectively to address critical social needs, and meet the daunting challenge of sustainable development. 